\title{
An interdisciplinary study of the seismic exposure dynamics of Santiago de Chile
}

\section{Felipe Rivera ${ }^{1}$, Tiziana Rossetto, John Twigg}

EPICentre and USAR, Department of Civil, Environmental \& Geomatic Engineering, University College London, United Kingdom

\begin{abstract}
This paper presents an interdisciplinary study on the spatiotemporal dynamics of seismic exposure. Out of the three components of risk-hazard, exposure, and vulnerability-exposure is the least studied, and is commonly treated as being constant in time. This approach neglects the dynamics associated with rapid development and urbanization, misrepresenting exposure in risk assessments. In this paper, mixed research methods are used to understand the dynamics of exposure in Santiago, the capital of Chile, between 1992 and 2017. First, residential exposure is modelled for three epochs using census data and public databases. Then, semi-structured interviews are conducted with local experts in engineering, planning, and disaster risk reduction to unveil the role of earthquake risk information in urban policy and development. Results show a steady expansion and densification of the city over the last 25 years, which is expected to continue in the future. The preferred building material for this growth is reinforced concrete, which rises from 3 to $17 \%$ as a proportion of the total structures in the city. It is also found that urban planning policy is disconnected from earthquake risk, which is perceived as a non-issue due to high local compliance with seismic codes. Thus, the continuous growth and homogenization of the built environment creates a singular dependence and blind trust in the local seismic academic and professional communities to provide earthquake resilience through safe buildings. These conditions configure a fragile but highly enabling environment for increasing seismic resilience in the city.
\end{abstract}

Keywords: exposure, interdisciplinary research, mixed methods, seismic risk, semi-structured interviews, spatiotemporal dynamics

\section{Highlights}

- Exposure modelling is used to bridge engineering, risk assessment, and urban planning

- The Chilean approach to tackle its seismic condition is solely via safe buildings

- Seismic hazard and risk are not considered in urban development and planning policy

- New evidence about Santiago's seismicity is challenging this traditional approach

- Santiago presents an enabling yet fragile environment for increasing seismic resilience

\footnotetext{
${ }^{1}$ Corresponding author (ucesriv@ucl.ac.uk). Department of Civil, Environmental and Geomatic Engineering, University College London. Gower Street, London, WC1E 6BT, United Kingdom.
} 


\section{Introduction}

Chile is regarded as one of the most seismic countries in the world (Scholz 2002). Since 1900, 81 destructive earthquakes of moment magnitude $\left(\mathrm{Mw}_{\mathrm{w}}\right) 7.0$ or larger have been recorded in the country with five of these exceeding magnitude $M_{w} 8.0$ in the past 25 years (CSN 2020). Earthquakes play a crucial role in shaping and strengthening the Chilean state, its institutions, legal framework, and disaster risk reduction (DRR) capacities (Gil 2016). The creation of the National Seismological Service and the National Emergency Office (ONEMI), and the constant update and enforcement of seismic design standards are only a few examples of the Chilean seismic institutional heritage (de la Llera et al. 2018). By learning its seismic lessons, Chile is acknowledged today as one of the most earthquakeresilient countries in the world (Stein and Toda 2013).

Earthquakes are a part of the geophysical context where cities develop. Chile has been mostly urban since the mid-20 $2{ }^{\text {th }}$ century and the urbanization rate has steadily increased in the last decades to reach almost 90\% (UN DESA 2018). Today, more than half of the 17.5 million people living in the country are clustered in only three large metropolitan areas, namely Santiago, Valparaíso, and Concepción. Moreover, population is largely concentrated, with more than $40 \%$ of the national population residing in the Metropolitan Region of Santiago (INE, 2018). With the constant threat of an urban disaster, it is of paramount interest to understand how and why Chilean cities are growing so as to better characterize future disaster risk.

\subsection{Seismic risk and urban studies in Santiago}

Essentially, seismic risk assessment (SRA) comprises three elements: hazard, exposure, and vulnerability. Seismic hazard is the probability of exceeding certain ground shaking intensity at a specific site in a determined timeframe. Seismic exposure is referred to as the set of elements or assets (e.g., people, buildings, systems) which are present in a hazard zone and are potentially subject to losses due to the effect of earthquakes (Pittore et al. 2017). Vulnerability combines the two, assessing the expected performance of the exposed assets under the effects of a seismic hazard event.

Research about seismic risk in Chile has focused on the hazard and vulnerability components of risk, while exposure has been somehow neglected. This has led to an underrepresentation and a lack of understanding of the contribution of exposure to risk. Recent hazards research for Santiago has focused on characterizing the San Ramón fault (SRF) and the soils of the city to produce and update seismic hazard maps (e.g., Rauld et al. 2015). The SRF runs across Santiago for more than $30 \mathrm{~km}$, and evidence of its activity has only started to be produced since 2004 (Vargas Easton et al. 2018). The characterization of the fault and its rupture potential are still in their early stages. However, it has been estimated that the SRF could produce an earthquake with magnitude up to $\mathrm{M}_{w} 7.5$ and local accelerations up to three times larger than those experienced in the $M_{w} 8.8$ Maule earthquake from 2010 (Vargas Easton et al. 2018). In the case of vulnerability, research is slowly shifting from the characterization of structural elements to the development of analytical and empirical fragility curves for structures (e.g., Cabrera et al. 2018). While this research is not specific to Santiago, it can be applied there since the studied typologies are widespread in the city.

Exposure models of Chile are scarce. Instead of focusing on the unique local challenges of exposure modelling, researchers generally model exposure as a (minor) input for risk calculation. Therefore, detailed discussion of the modelling process and presentation of the exposure results are very limited and almost absent in the literature (e.g., Cardona et al. 2017; Pina and González 2014; Vaziri et al. 2012). The majority of existing studies use census data in combination with other public databases to model exposure. This approach has been used by Santa María et al. (2017) to generate an exposure model of residential structures for the whole country with a census-block resolution, and by Aguirre et al. (2018) to develop a detailed building-by-building exposure model of the city of Iquique. Remote 
sensing data have also been used for exposure modelling. A simple method involving remote assessment of Google StreetView images has been used by Santa María et al. (2017) to model three medium-size Chilean cities. A more sophisticated method has tested the joint use of remote sensing data and volunteered geographical information to model the city of Valparaíso (Geiß et al. 2017). Exposure models of Santiago are even more limited and only the one developed by Santa María et al. (2017) is fully available to be used for SRA-related purposes. This model, however, is only meant to represent the residential built environment of the city for 2014 and its applications are therefore limited.

One of the limitations of SRA consists in assuming that each of its components remains static in time. However, this is rarely the case. Physical changes in infrastructure such as aging, retrofit, expansion, or other alterations may result in reduced or increased vulnerability (Lee et al. 2018). Furthermore, the dynamics of urban contexts, including rapid urbanization, population growth, and urban sprawl, swiftly modify exposure in cities over time. Neglecting this effect results in a misrepresentation of exposure's contribution to risk and therefore hinders SRA accuracy (Geiß et al. 2017; Pittore et al. 2017). Time-dependent or dynamic SRA requires looking at risk components in a different way. For exposure, this means understanding its spatiotemporal dynamics.

Beyond SRA-related research, a review of the relevant literature about Santiago shows that most research falls into one of two clusters. The first deals mainly with the city's development and its conflicts in terms of access, exclusion, regulation, and governance (e.g., Boano and Vergara-Perucich 2017; Galetovic 2006; López-Morales 2016; Vicuña Del Río 2017). Whilst indispensable to understand the underlying processes shaping Santiago, this research is not directly connected to natural hazards or risk. The second cluster aims to fill this gap. However, the natural phenomena under study are mostly related to water in the context of flooding (e.g., Banzhaf et al. 2013) and socio-environmental conflicts (e.g., Aliste and Stamm 2017; Romero et al. 2012). Only a recent work by Vargas Easton et al. (2018) presents a multi-disciplinary study addressing Santiago's growth under the recent evidence of seismic activity in the SRF. The authors have estimated that ca. $45 \%$ of the SRF trace has not been yet urbanized, proposing that regulatory changes should be enacted to preserve the current urbanization level near the fault's trace to mitigate the potential impacts of a future earthquake (Vargas Easton et al. 2018).

From the reviewed literature, two major research gaps are identified. First, the need to improve efforts on exposure modelling for SRA purposes considering its spatiotemporal dynamics. Second, the need to link the underlying causes of urban phenomena with their seismic risk consequences.

Contributing to fill these gaps, this paper presents the results of an interdisciplinary research on the spatiotemporal dynamics of seismic exposure in the city of Santiago. Mixed research methods, presented in Section 3, are used to (i) quantify how much the built environment of the city has changed between 1992 and 2017, (ii) explore its relationship with urban planning decisions, and (iii) unveil the role of risk information in urban development policy. Section 4 summarizes the quantitative and qualitative results separately. These results are brought together in Section 5 in a discussion about their meaning and implications for the current and future seismic resilience of Santiago. Finally, concluding remarks are presented.

\section{The city of Santiago}

Santiago, often referred to as Gran Santiago (Greater Santiago), is the capital and most important city of Chile. It lies at the core of the Metropolitan Region of Santiago (MRS), which is administratively divided into 6 provinces and 52 comunas (Fig. 1). ${ }^{2}$ Although each province and comuna is well delimited, there is no formal definition of Santiago's limits. Greater Santiago is commonly associated with the conurbation of 34 comunas of the MRS, the 32 in the core-which correspond to the

\footnotetext{
${ }^{2} \mathrm{~A}$ comuna is the smallest administrative level in Chile, which government receives the name of municipality.
} 
Santiago Province-together with the comunas of Puente Alto and San Bernardo. This definition is used both in official documents and research. Nevertheless, it is also common to find alternative definitions of Greater Santiago, expanding the notion of the city to more than 40 comunas (e.g., MINVU and INE 2018).

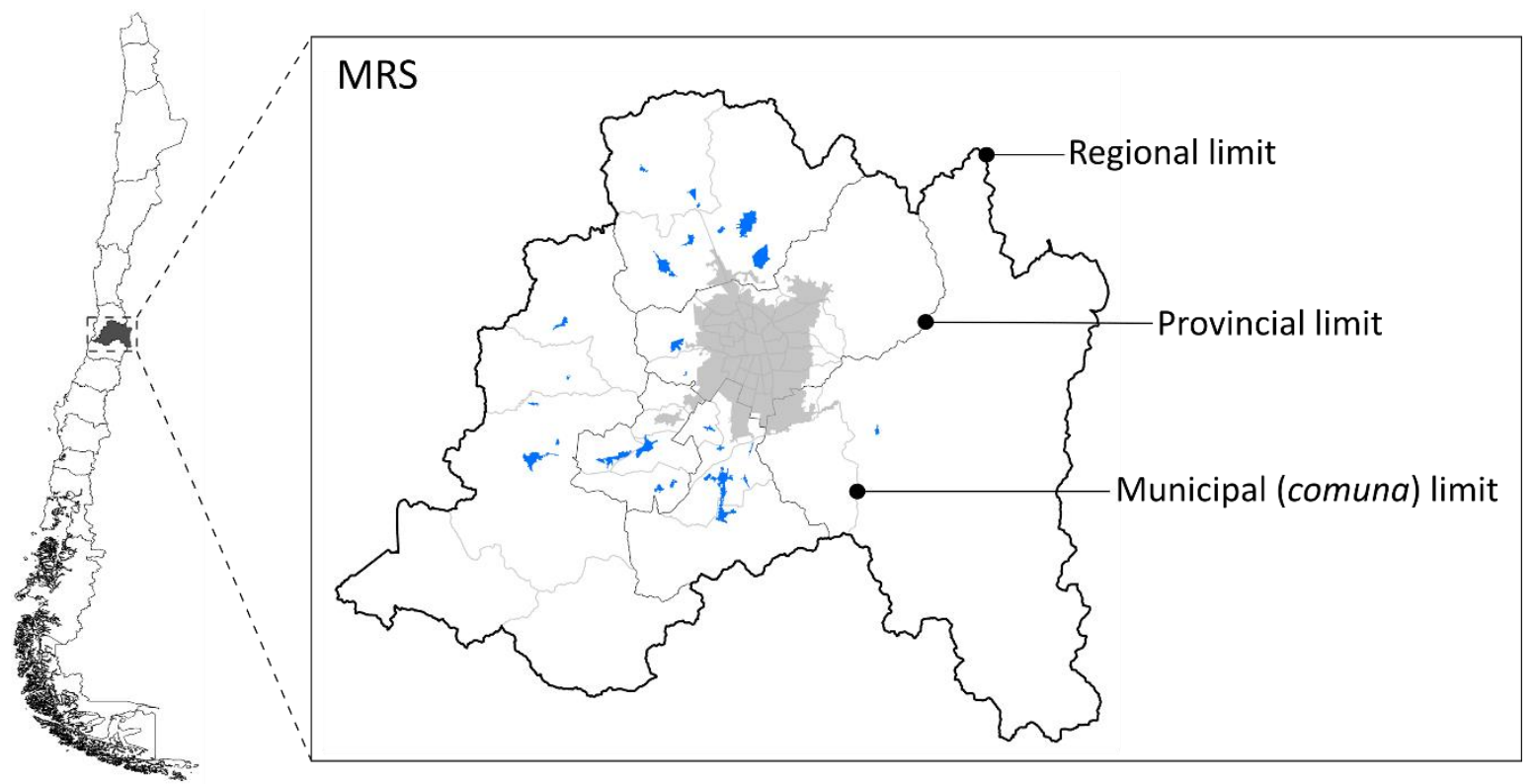

Fig. 1 The Metropolitan Region of Santiago (MRS) is divided into six provinces (dark grey lines) and 52 comunas (light grey lines). The main Consolidated Urban Area (CUA) of Greater Santiago (in grey) extends beyond communal or provincial limits to include 40 comunas either completely or partially. The secondary CUAs (in blue) constitute isolated urban pockets spread over 16 comunas. Source: CUAs from MINVU \& INE (2018).

Over time, several peri-urban comunas of the MRS have become dormitory towns of Greater Santiago. Some of these have become a part of Santiago's main Consolidated Urban Area (CUA) while others remain detached but are functionally connected (Fig. 1). To account for this, this research adopts as the case study the Santiago Urban Metropolitan System (SUMS) defined by de Mattos et al. (2014). To define the SUMS, the authors use the criterion proposed by OECD (2012) where a periurban comuna is considered a part of the urban system if at least $15 \%$ of its population commutes from its core to the core of Greater Santiago. With 13 comunas outside Greater Santiago meeting this criterion, the SUMS comprises 47 out of the 52 comunas in the MRS and is divided into four concentric areas (Fig. 2): the Historic Centre (HC) which corresponds to the Santiago comuna, the First Crown $(\mathrm{FC}$ ) which comprises the 22 comunas around the HC, the External Crown (EC) comprising 11 comunas around the $\mathrm{FC}$, and the Extended Peri-urban (EP) comprising the 13 comunas in the external ring of the SUMS (de Mattos et al. 2014). The remaining 5 comunas are not considered in this research. Defining the city in this way allows to observe urban growth by means of both horizontal expansion and vertical densification in time. 


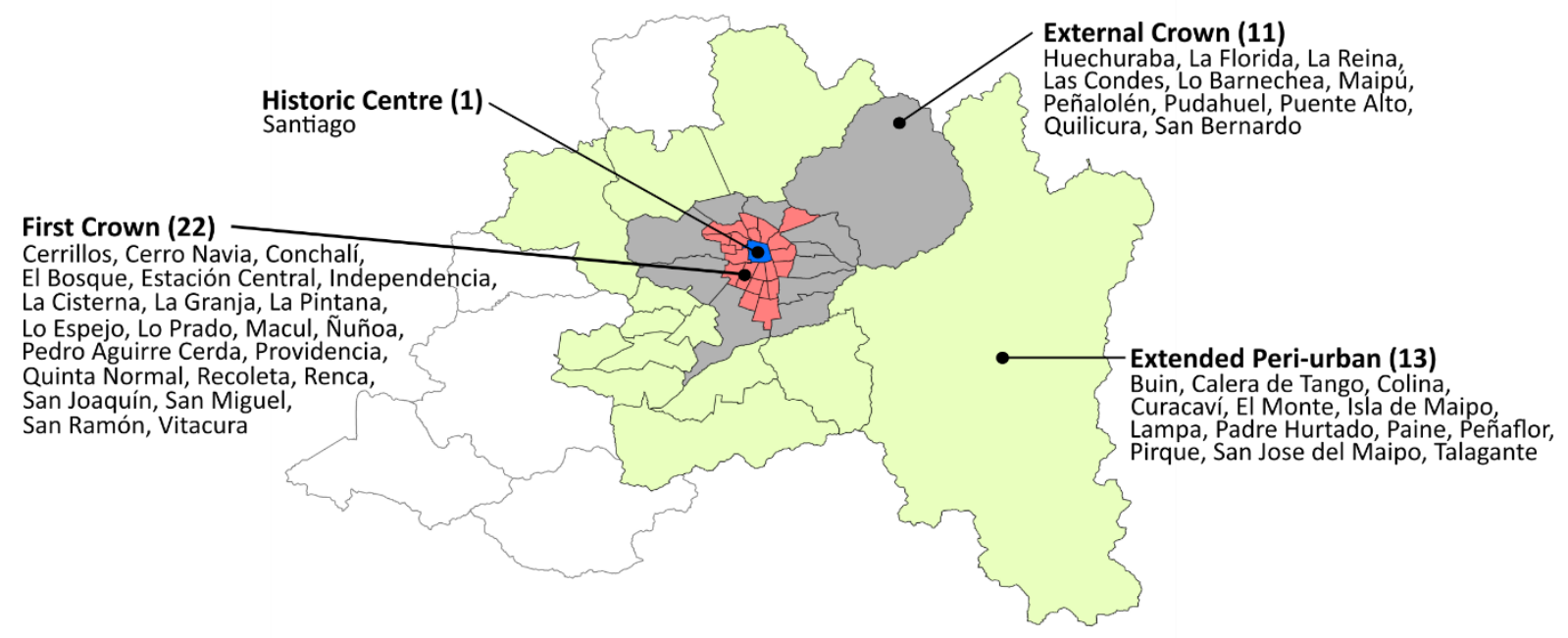

Fig. 2 The Santiago Urban Metropolitan System (SUMS) comprises 47 out of the 52 comunas of the MRS and is composed of four concentric rings: Historic Centre (HC), First Crown (FC), External Crown (EC), and Extended Peri-urban (EP).

\section{Methodology}

Characterizing and understanding the spatiotemporal dynamics of a city pose questions which are essentially interdisciplinary. A mixed methods research approach is therefore used, involving the use, combination, and integration of different elements of qualitative and/or quantitative research (Plano 2017). Firstly, quantitative methods are used to model the temporal dynamics of seismic exposure in Santiago and quantify these changes. Next, qualitative methods are used to shed light on the role of seismic risk and natural hazards information as drivers for urban development policy. This methodological approach is intended to contribute to bridge engineering, risk assessment, and urban planning, three key disciplines in DRR.

\subsection{Modelling seismic exposure}

To study the spatiotemporal dynamism of Santiago from a seismic risk perspective, three exposure models of the city in different epochs are compared. The study period is defined between 1992 and 2017. The exposure models represent the built environment of 1992, 2002, and 2017. Only residential buildings are considered, which comprised $65 \%$ of the total built surface in the MRS between 1990 and 2014 (Vergara 2017), and 99.8\% of the total building stock in the region in 2017 (INE 2018).

\subsubsection{Data sources}

Chile lacks an aggregated database with historic information on the built environment. Instead, all relevant data are collected and stored separately, in different formats, by different public institutions (e.g., local governments, ministries, public services). Although using census data is an alternative to overcome this obstacle, it constitutes an inefficient approach to model seismic exposure (Pittore et al. 2017). Regardless, global efforts for exposure and risk modelling such as the Global Earthquake Model (GEM) still rely heavily on local census data and expert knowledge (Silva et al. 2018). In this study, the 1992, 2002, and 2017 censuses are chosen for developing the exposure models. From the census, three data fields are used: (i) number of dwellings at different geographical levels (e.g., comuna, census block); (ii) technical information of dwellings (i.e., dwelling type, main exterior wall material, and main roof covering material); and (iii) census cartography. Only permanent residential buildings 
are considered for the exposure model, so mobile dwellings (e.g., tents, house trailers) were removed from the database.

Census data are not collected for the purpose of exposure modelling, lacking the detail required to directly characterise building types according to their vulnerability. Hence, some level of interpretation is necessary. Building typologies in Chile are fairly uniform due to the widespread use and enforcement of building standards (Contrucci 2008). Hence, it is relatively straightforward and accurate to determine the structural system of a dwelling based only on information of its main wall material, which is available from the census (Santa María et al. 2017). However, there are two main limitations for using census data for exposure modelling. First, its technical accuracy. Census data are provided by the residents, so technical information such as wall and roof covering material can be inaccurate. Second, data are recorded for dwellings whereas exposure is represented at the level of independent buildings or structures. Except for detached houses, there is no direct correspondence between the number of dwellings and the number of buildings. To overcome this, supplementary data are used throughout the exposure modelling process to perform an informed dwelling-tobuilding aggregation process (see Section 3.1.2). Three data sources are used for this: the Edification Statistics Database (ESD), the 2012 census, and the database of social housing of the Ministry of Housing and Urbanism (MINVU).

The ESD integrates the information from the Formulario Único de Estadísticas de Edificación (Unique Form of Edification Statistics, FUEE) and is managed and maintained by the Instituto Nacional de Estadisticas (National Institute of Statistics, INE). The FUEE is presented to the corresponding municipality-local government-when applying for a construction permit. Once the permit is granted, the information of each construction permit is incorporated into the ESD. The ESD used in this research comprises the construction permits issued between January 2002, when the database was implemented, and July 2014.

The 2012 census was declared invalid after important mistakes were identified in its design, implementation, and processing (Bravo et al. 2013). It was therefore dismissed as a reliable source for creating an exposure model for 2012. However, the database still has a high coverage (almost 90\%) and provides valuable information to back up some modelling assumptions.

MINVU's database of social housing projects is open and available at the Chilean Geospatial Data Infrastructure (IDE Chile). It has information about projects built, sponsored, and/or subsidized by MINVU, which are usually a combination of houses and apartment buildings conforming to a narrow group of architectural and structural typologies. The version of the database used in this research contains information on existing social dwelling complexes built between 1936 and 2015.

\subsubsection{Exposure modelling method}

Exposure models are built following an eight-steps method (Fig. 3). The method starts from dwelling counts from raw census data and finishes with building counts associated with different fragility typologies (FT). The FT are defined to represent the residential built environment of Santiago across epochs, which allows comparison. Supplementary data, relevant literature, and local expert knowledge are used to improve the quality and accuracy of the assumptions made in the different stages of the method. 
(a)

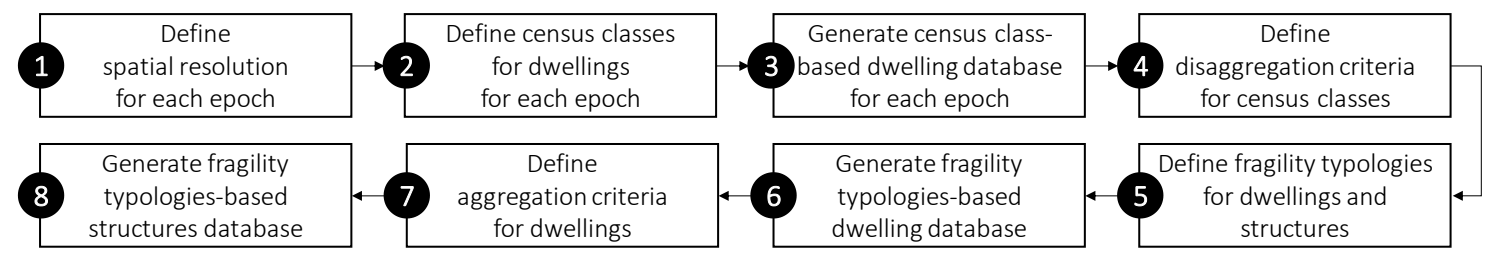

(b)

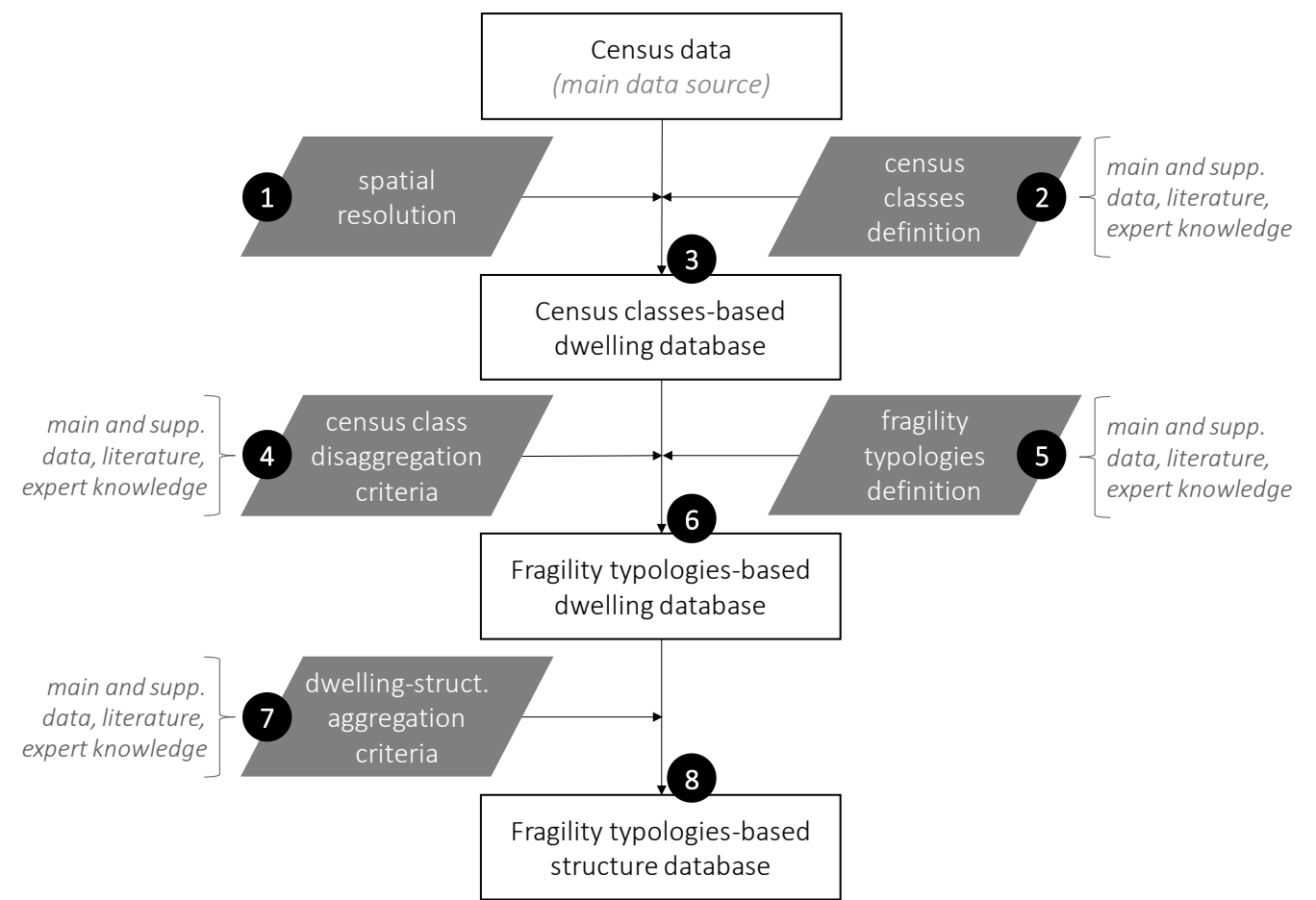

Fig. 3 (a) The process for exposure modelling has eight steps. (b) Throughout the method, raw census data pass through four different states (white blocks). Supplementary data define modelling criteria (grey blocks) used as inputs in each step.

First, the spatial resolution of the models is defined according to data availability. A resolution of manzana censal (census block) is used for 1992 and 2002 and a resolution of zona censal (census zone) for 2017. Santiago is thus divided into 37,195 census blocks in 1992; 46,449 census blocks in 2002; and 2,223 census zones in 2017.

Second, the census classes (CC) are defined. CC are auxiliary categories used to manage and classify the raw census data. Therefore, they are epoch-specific and apply only for dwelling counts (Fig. 4). CC are defined in two levels using census' technical information on dwellings: Level 1 corresponds to dwelling type (see Fig. 4, left column of each block), and Level 2 corresponds to the main exterior wall material (see Fig. 4, right column of each block). Level 1 definition of CC deals with census dwelling types changing in each census. However, the three main dwelling types have remained constant, namely house, flat, and rooms in conventillo. ${ }^{3}$ Three other dwelling types are defined to group the remaining dwellings, mostly corresponding to non-engineered constructions. These dwelling types are mediaguas (traditional timber emergency constructions), vernacular constructions (grouping dwellings classified as traditional indigenous dwellings, ranchos, chozas, and similar), and selfconstructed dwellings (Fig. 4). The CC are then defined by the main exterior wall material (Level 2 definition). The most commonly used materials across epochs are reinforced concrete (RC), clay brick and concrete block masonry, timber, and adobe (see Fig. 4). Other traditional materials are used for

\footnotetext{
${ }^{3}$ A conventillo (sometimes translated as tenement slum) is a large, old house with several rooms which are rented to different families who share common facilities such as bathroom, toilet, and kitchen.
} 
vernacular and informal constructions such as cob, mud, pirca, quincha, or waste materials. Thus, thirteen dwelling CC are defined for 1992, sixteen for 2002, and fourteen for 2017.

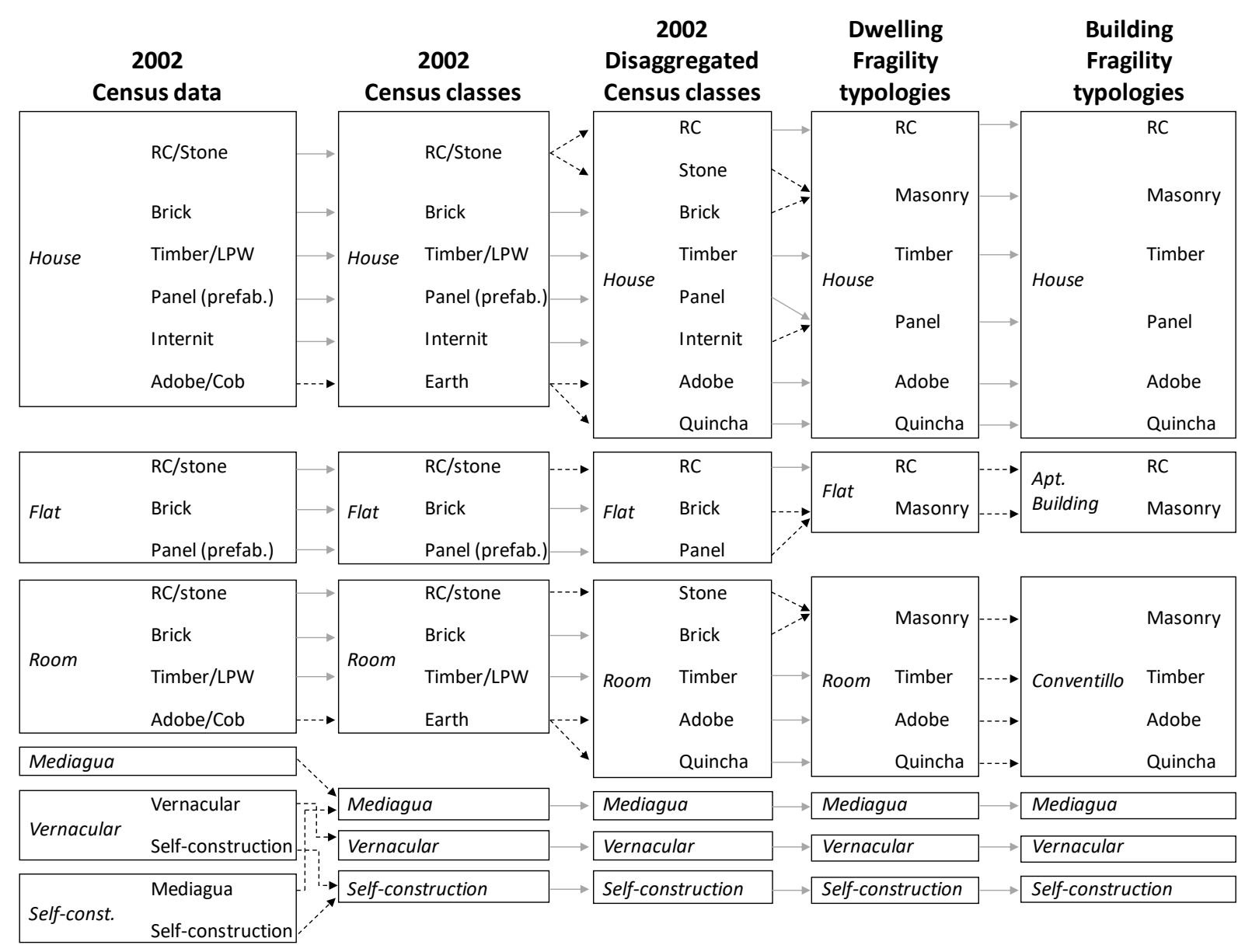

Fig. 4 The 2002 census data pass through five states and several categories during exposure modelling. It goes from 18 raw census categories, to 16 census classes (CC), to 19 disaggregated CC, to 15 dwelling and building fragility typologies (FT). Dotted lines identify categories being aggregated/disaggregated in the process. $R C$ stands for Reinforced Concrete, $L P W$ stands for Lined Partition Wall.

The third step consists of producing a database for each epoch by classifying the raw census data into the defined CC. A first version of the exposure models thus consists of a database of CC-based dwelling counts, where rows corresponds to spatial units (i.e., census blocks or zones) and columns represent the CC. For example, the database for 2002 has 46,449 rows and 16 columns (i.e., the 16 categories in the second column in Fig. 4).

Fourth, the criteria for disaggregating the CC data are set. This is necessary because some CC group more than one type of dwellings. For example, in 2002, the RC/stone house dwelling CC groups RC with stone houses despite they correspond to different FT (Fig. 4). This also happens with other dwelling types (flats and rooms) and in other epochs. Hence, different criteria are set to disaggregate CC data into the FT using main and supplementary data, expert knowledge, and literature. For example, considering that there are no multi-story apartment buildings built with stone walls in Santiago, all the dwellings in the RC/stone flat dwelling CC are classified as RC flats (Fig. 4). For other classes, data of main roof covering material from the census are used.

The fifth step sees the definition of the FT, corresponding to the categories into which the disaggregated CC data are classified. Like CC, FT are defined at two levels: dwelling type and main 
exterior wall material (Fig. 4). Fifteen FT are defined for Santiago: six for house dwellings (RC, masonry, timber, panel, adobe, and quincha), two for flat dwellings (RC and masonry), four for room dwellings (masonry, timber, adobe, and quincha), one for mediagua, one for vernacular, and one for self-constructed dwellings.

With the criteria and categories to disaggregate the data, the sixth step consists of producing a second database for each epoch. These databases consist of FT-based dwelling counts, where rows correspond to spatial units and the 15 columns represents the FT. For example, in 2002, dwellings in the $R C$ /stone house dwelling CC are first disaggregated into RC or stone houses (steps four and five), and then classified into the RC houses or Masonry house FT (step six), respectively (Fig. 4).

To obtain the final version of the models, it is necessary to estimate the number of buildings in each spatial unit from dwelling counts. For this purpose, the seventh step consists of a dwellings-tobuildings aggregation process. Note that no additional FT are defined; instead, flat FT are replaced by apartment building FT, and room FT are replaced by conventillo FT (Fig. 4). Different aggregation parameters are used for each comuna and building material. For dwellings in the mediagua, vernacular, and self-construction $\mathrm{FT}$, the aggregation parameter is 1 , meaning that one dwelling corresponds to one independent structure. For houses, dwellings are aggregated as detached (i.e., aggregation parameter of 1), semi-detached, or continuous house structures (i.e., aggregation parameter $<1$ ). Flat dwellings are aggregated into multi-story apartment buildings (Fig. 4). Room dwellings are aggregated into conventillo structures. The details of the calculations and the value of the aggregation parameters (i.e., how many dwellings of certain FT are considered to constitute a structure of that FT) can be found in Rivera (2018).

Finally, the eighth step of the method consists of generating the exposure model for each epoch by aggregating dwellings into structures for each FT. The exposure models are thus FT-based structure databases where each row corresponds to a spatial unit and each column represents a different building FT (Fig. 4).

\subsection{Linking natural hazard risks and urban development}

Although exposure modelling provides significant information to understand how Santiago has grown in time, it does not answer why. Qualitative research is used to understand the role of earthquake risk information in the physical evolution of Santiago. Sixteen semi-structured interviews are conducted with local experts for this purpose. Although the number of participants may seem low, it is important to note that, unlike quantitative research, qualitative research is normally not concerned with generalizing the findings coming from the subjects under study. Instead, interviews are used as a tool to access to information otherwise unavailable (McCracken 1988). The qualitative interview is not concerned with knowing how many and what kind of people share a specific characteristic or idea. Instead, it aims to uncover categories and assumptions, and not necessarily identify or characterize those who hold them (McCracken 1988). Additionally, the professional and academic communities in Chile are relatively small. Experts are usually in academia from where they participate as consultants and advisors for public policy and professional practice in both public and private sectors.

One of the most important limitations of this method is that qualitative research is person-based. Therefore, access to people and organizations as well as production, collection, processing, and interpretation of data are influenced by the person conducting the research and those participating in it. Also, the combination of data from different stakeholders proves challenging and may sometimes be conflicting. However, this research does not intend to be representative of all the urban conflicts in the city, but to unveil key themes regarding DRR and seismic resilience. 


\subsubsection{Selection of participants}

The population of interest for this research are local experts in fields related to seismic risk and resilience. The inclusion criteria are that participants have a professional degree or formal training and renowned academic and/or professional experience working in at least one of the fields of earthquake engineering, construction, structural design and building code development, urban planning, real estate development, urban resilience, DRR, and public administration at national, regional, or local levels. The final interviewee list is limited to 16 people representing different stakeholders and groups of interest. Out of the 16 interviewees, two are female and 14 male. All but one interviewee are Chilean, although the one who is not has lived and worked in Chile for more than 20 years. Despite some of the experts having worked and served as consultants abroad, their main area of work and expertise is Chile. All of them have vast local knowledge on project development, legal framework, public policy, and/or research. Six of the interviewees are full-time academicsthree engineers, three architects - who also participate in consultancy for the private and public sectors. Four interviewees have developed their careers as practitioners: two of them-an architect and an engineer-closely related to academia through teaching, research, and administrative duties; the other two are engineers, one with a career in real estate development, and the other is a representative of the association of cement and concrete companies. The remaining six-one lawyer, one public administrator, one DRR expert, and three architects-have worked mainly in the public sector; three of them in municipalities, one in a ministry and later at ONEMI, and the other two in different positions in local, regional, and national government administrations.

\subsubsection{Interview procedure}

The interviews took place in Santiago between March and April 2018. They were conducted in a place convened with the interviewee, generally in their workplace. Prior to the interview, an informed consent was signed. Data were collected by means of semi-structured, long qualitative interviews (McCracken 1988). Interviews were conducted in Spanish with a topic guide for overall direction. All the interviews were recorded to allow later processing. The main topics addressed in the interviews were: (i) drivers of urban growth and development in the MRS, (ii) risk-informed decision- and policymaking in a DRR context, and (iii) tensions between different levels of administration regarding urban planning and DRR.

Acknowledging that certain DRR-related terms (e.g., risk, vulnerability) can be defined differently across disciplines, some of the questions specifically addressed definitions. Prompts such as "what/who do you mean by that" were used to deepen answers where the interviewee assumed specific knowledge. These prompts were also used to encourage the interviewees to expand certain topics which are relevant to their daily work but may have been considered distant from the main goals of the interview. The interviews lasted between 42 and 108 minutes with an average of 67 minutes. The initial 10 to 15 minutes of each interview inquired about personal information such as family background and educational and professional history of the interviewee. This allowed a first, more informal contact with the interviewees to set a more relaxed tone for the remaining of the interview. After the interview, interviewees were asked to provide their feedback on the process.

\subsubsection{Data analysis}

The post-processing of the interviews is done with thematic analysis. This allows the identification and analysis of the main patterns of meaning in a dataset, highlighting the important themes to describe the phenomenon under study (Joffe 2012). For this analysis, the recordings of the interviews are divided into multiple 30-second slots. The main ideas discussed by the interviewees in each slot are identified, and a code or keyword is assigned to each of these ideas. These codes are then put together to create a topic map of the interview. With the use of notes made during, and summaries 
made after each interview, the maps are analysed to identify the more frequently observed topics. Common topics are grouped to form the key themes arising from the set of interviews. Finally, the recordings of the interviews are translated into English by the authors, obtaining the quotes presented in the article to represent those themes.

\section{Results}

\subsection{Exposure modelling}

The exposure models support three main results. The first is that Santiago's residential exposure is increasing over time. An overview of the 1992, 2002, and 2017 censuses and exposure models shows a steady increase of total population, dwellings, and structures (Table 1). While population has grown 15\% between 1992 and 2002 and 17\% between 2002 and 2017, dwellings have increased by 25\% and $40 \%$, and structures in $13 \%$ and $22 \%$ in these years, respectively. A larger increase of dwellings as compared to number of structures indicates densification, with the average ratio of dwellings-tobuildings rising from 1.6 to 2.0 in 25 years.

Table 1 Overview of the 1992, 2002, and 2017 censuses (population and dwellings) and exposure models (buildings) for every area of the Santiago Metropolitan Urban System (SUMS). HC stands for Historic Centre, FC for First Crown, EC for External Crown, and EP for Extended Peri-urban.

\begin{tabular}{llc|ccc|ccc}
\hline \multirow{2}{*}{ Epoch } & & \multicolumn{3}{c|}{ Inner SUMS } & \multicolumn{3}{c}{ Outer SUMS } \\
\hline 1992 & & (number) & HC (\%) & FC (\%) & HC+FC (\%) & EC (\%) & EP (\%) & EC+EP (\%) \\
\cline { 3 - 8 } & Dwellings & $1,200,832$ & 5 & 53 & 58 & 35 & 7 & 42 \\
& Buildings & 742,590 & 3 & 52 & 55 & 35 & 10 & 45 \\
\hline 2002 & People & $5,929,563$ & 3 & 44 & 47 & 44 & 9 & 53 \\
& Dwellings & $1,498,769$ & 4 & 43 & 47 & 44 & 9 & 53 \\
& Buildings & 842,318 & 2 & 43 & 45 & 43 & 12 & 55 \\
\hline & People & $6,940,109$ & 5 & 39 & 44 & 44 & 12 & 56 \\
& Dwellings & $2,090,848$ & 8 & 39 & 47 & 42 & 11 & 53 \\
& Buildings & $1,025,695$ & 2 & 35 & 37 & 45 & 18 & 63 \\
\hline
\end{tabular}

Although there is an overall growth in the number of structures and people in Santiago, this is mainly seen to occur in the two external areas of the city, the EC and EP (Fig. 5). Whereas $43 \%$ of the population lived in these areas in 1992, 56\% did it in 2017 (Table 1). Moreover, these areas concentrate only $45 \%$ of the structures of the city in 1992 , but $63 \%$ by 2017 . Whilst it is the EC that sustains most of the growth in the first 10 years (increase of $9 \%$ of population and $8 \%$ of structures between 1992 and 2002), the EP does it in the last 15 years (increase of 3\% of population and 6\% of structures between 2002 and 2017). 


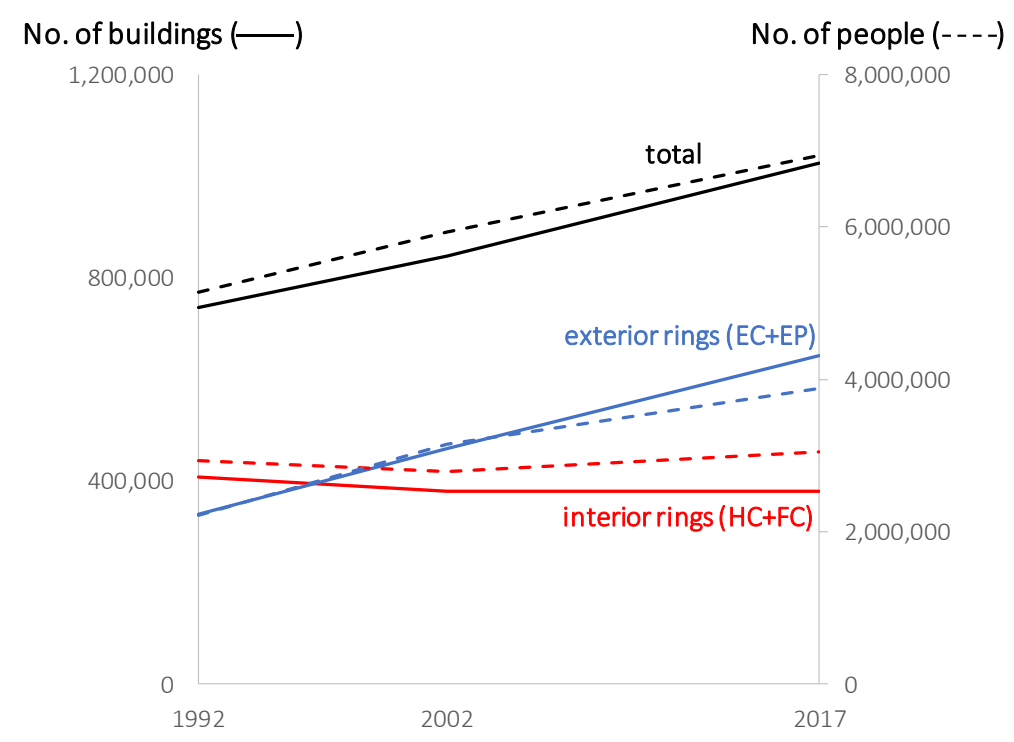

Fig. 5 The external rings of the SUMS (EC and EP) explain most of the growth in time. The inner rings (HC and FC) stay essentially constant in the study period. Solid lines represent buildings ( $b$, left vertical axis); dotted lines, population ( $p$, right vertical axis).

The exposure models also show that houses and apartment buildings represent a combined $85 \%$, $92 \%$, and $96 \%$ of the total structures in each epoch. However, houses are by far the predominant first-level structural fragility typology. On average, houses represent $88 \%$ of the total structures whereas apartment buildings only account for $3 \%$. There are almost no apartment buildings in the EP, which expands mainly through large real estate projects of houses. Apartment buildings increase their share of the total structures when moving towards the centre, reaching $8 \%$ in the HC across epochs. Other typologies such as conventillos, mediaguas, vernacular, and self-constructed structures represent, together, $12 \%$ in 1992 but only $3 \%$ of the total in 2017, indicating urban renewal, a homogenization of the built environment, and the progressive loss of traditional construction modes. This can also be interpreted as a step towards formalization of the built environment and therefore an expected increase in seismic safety.

From these observations follows the second main result from the exposure models: that the city is growing both horizontally and vertically, i.e., it is expanding and densifying in parallel. As expected, the models show that expansion is predominant in the exterior of the city (EC and EP) while densification is more intensive in the centre (HC and $\mathrm{FC}$ ). Regarding expansion, the total number of houses is increasing in time and quickly concentrating in the external rings of the city (Fig. 6). Regarding densification, the censuses show that the proportion of house dwellings has decreased with time in every area of Santiago except for the EP. Noteworthy is the case of the HC, where house dwellings decrease to less than a third in 25 years. Instead, flat dwellings are on the rise for every area of the city; the share of flats from the total has doubled in the HC, FC, and EC (Fig. 7, solid lines). However, the proportion of apartment buildings to total structures stays relatively constant in time (Fig. 7, dashed lines). Proportionally more flat dwellings (apartments) with a constant share of apartment building structures means a densification of the building stock. While densification is more intensive in the centre of the city (i.e., $\mathrm{HC}$ and $\mathrm{FC}$ ), the $\mathrm{EC}$ also densifies but with lower heights. 
Total no. $1,000,000$ of houses

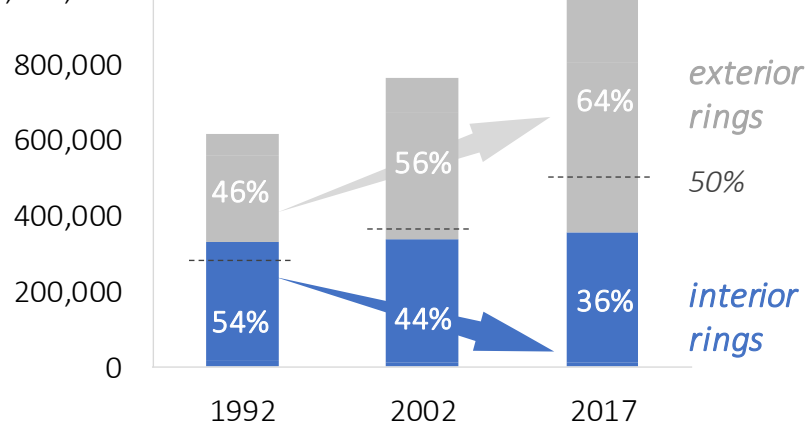

Fig. 6 Although the total number of houses increase in time, they start concentrating predominantly in the external rings of the city (EC and EP).

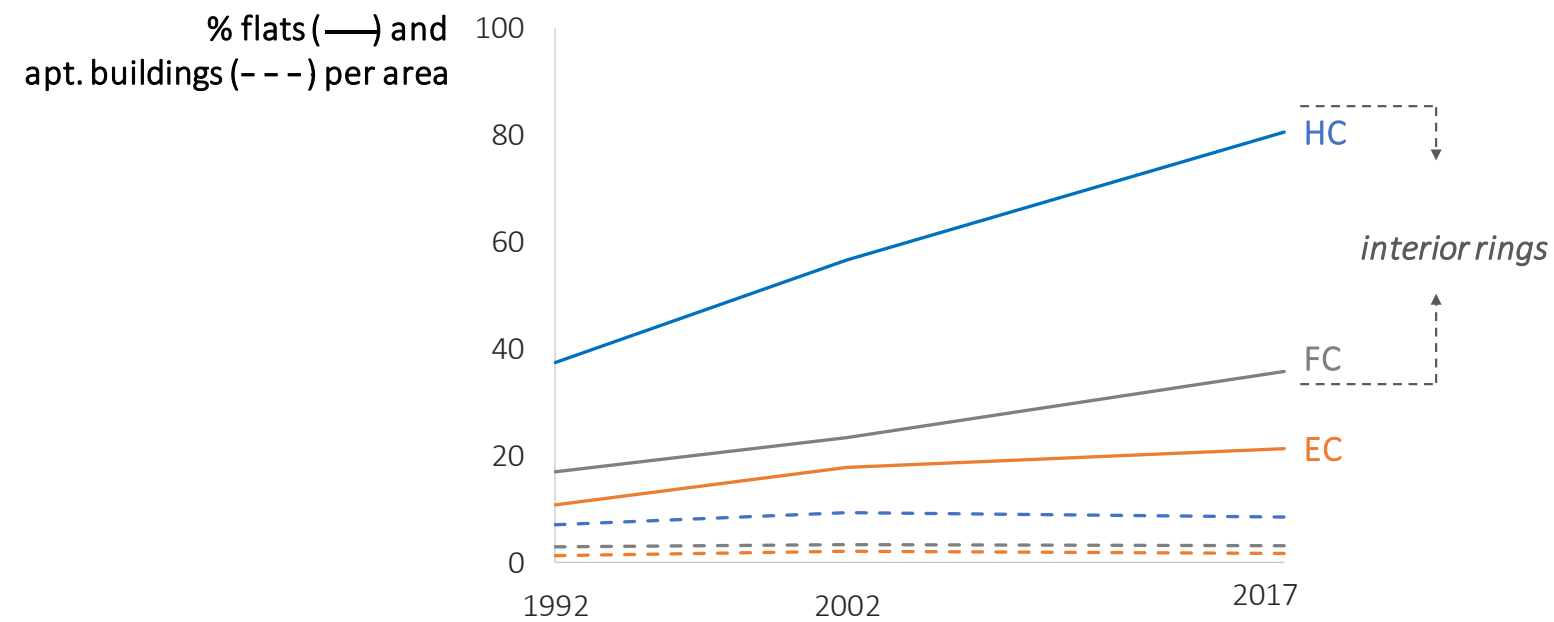

Fig. 7 The models estimate that the ratio of apartment buildings to total structures remains constant in time, but with denser structures.

The third main result from the models is that Santiago is evolving into a city where reinforced concrete $(\mathrm{RC})$ is becoming the preferred building material. Overall, only $3 \%$ of the total buildings in the city are made of RC in 1992, whereas this rises to 6\% in 2002, and to 17\% in 2017 (Table 2). RC houses represent almost 3\% of the total buildings in 1992, 5\% in 2002, and almost 17\% in 2017. Instead, the number of RC apartment buildings only represent $\sim 1 \%$ of the building stock across epochs despite the number of RC flat dwellings tripling in the 25 years, implying high density of flats per building (Table 2). The models also reveal that the rise of RC as main building material runs across the city and is not exclusive of either the centre or the periphery. In the inner rings of the city, RC dominates as new mid- and high-rise apartment buildings (densification); in the outer rings, RC comes in the form of houses (expansion). 
Table 2 Overall use of RC as building material has intensified in the last 15 years in Santiago by means of replacement of old buildings in the inner areas, and the development of new large housing projects in the outer areas of the city.

\begin{tabular}{c|cc|cc|cc}
\hline & \multicolumn{2}{|c}{1992} & \multicolumn{2}{c|}{2002} & \multicolumn{2}{c}{2017} \\
& (num) & (\%) & (num) & (\%) & (num) & (\%) \\
\hline Total dwellings & $1,200,832$ & 100.0 & $1,498,769$ & 100.0 & $2,090,848$ & 100.0 \\
Total RC dwellings & 110,440 & 9.2 & 245,491 & 16.4 & 683,738 & 32.7 \\
RC house dwellings & 22,739 & 1.9 & 57,395 & 3.8 & 225,877 & 10.8 \\
RC flat dwellings & 87,701 & 7.3 & 188,096 & 12.6 & 457,861 & 21.9 \\
\hline Total structures & 742,590 & 100.0 & 842,318 & 100.0 & $1,025,695$ & 100.0 \\
Total RC structures & 23,751 & 3.2 & 52,895 & 6.3 & 176,179 & 17.2 \\
RC houses & 19,699 & 2.7 & 45,712 & 5.4 & 169,974 & 16.6 \\
RC apt buildings & 4,052 & 0.5 & 7,183 & 0.9 & 6,205 & 0.6 \\
\hline
\end{tabular}

\subsection{Understanding the development trend}

Building on the exposure analysis, the interviews highlight three major themes: (i) why Santiago grows, (ii) how does urban development policy address natural hazards, and (iii) who is responsible for seismic risk. These themes shed light on the development trends and on attitudes towards riskinformed planning and development.

\subsubsection{Santiago is an attraction pole}

According to the experts interviewed, Santiago grows simply by following Chile's growth. With Santiago as the main city of a highly centralized country, Chile's overall growth is directly expressed in the capital. The country's sustained economic growth in recent decades has carried a demographic growth in the capital. Santiago is identified as an attraction pole and "economic magnet" [7] ${ }^{4}$, which was further stressed after the rural-to-urban migration in the first half of the $20^{\text {th }}$ century. People migrate to the city looking for better and more complex services and opportunities (e.g., education, healthcare, entertainment, jobs). Similarly, there are not many reasons for dwellers of Santiago to leave.

Economic growth translates into wealth. Wealth is identified by the interviewees as the most relevant factor for the demand of more and better housing, even more important than the population's increase. Urban growth occurs by means of expansion and densification, the "conditions of a dynamic city" [3]. On the one side, expansion is associated with the demand for suburban houses. The great connectivity provided by urban and interurban highways is regarded as one of the main reasons why housing away from the city centre is attractive. Additionally, certain exception rules in the urban regulation also explain the appearance of small urban centres disconnected from the continuous urban stain of Santiago in the last decades [1]. On the other side, densification arises from the demand for housing closer to the centre. The large impact that Transantiago-the public transportation system of Santiago implemented in 2007-had in the transportation times of people is identified by some interviewees as one of the main reasons increasing this demand and accelerating densification in the core of the city in the last 10 years $[2,12]$ (also in Vergara, 2017).

\subsubsection{Risk is not a driver for development}

The second theme addresses the interrelation between development, planning, and natural hazard risks. The first topic regards urban planning. Here, the transversal view across disciplines is that

\footnotetext{
${ }^{4}$ Number on brackets after each quote identifies interviewees in a unique and anonymized way.
} 
regulation and practice in Chile lag behind the needs of the city. Indeed, when first asked about urban planning, a common reaction amongst the interviewees is to address the discussion from a lack of planning perspective, which better reflects the reality of the country. Transversally, interviewees identify the excessive fragmentation of the Chilean public administration as one of the main causes leading to this. This hinders a long-term view in complex subjects such as city development, which is intrinsically multidisciplinary and intersectoral. The lack of a consistent framework for urban planning is regarded as a problem because planning instruments and plans are not linked to investment. Thus, the planning instruments do not constitute a strategic plan for development, but merely a set of rules regulating the development of private projects in the territory; a declaration of good intentions. In summary:

We are constantly solving gaps and deficit. First, we generate a city, and then we see how people would transport. It is not as Hong Kong where the development of subway is in front of the development of the city [...] that vision does not exist in Santiago. So, we are always managing or mitigating deficit [10].

The second topic is the lack of connection between planning and natural hazard risks. Again, the fragmentation of the public administration plays a part, with the lack of a city-level administration, and of strong DRR policy and institutional framework exacerbating this problem. Interviewees even express the opinion that the modifications to the law on regional governments passed on 2018 (Law $21,074)^{5}$ may worsen the situation by duplicating political power in metropolitan areas and large cities such as Santiago, which could be chaotic in a disaster situation. Regarding how urban DRR should be tackled by the public administration, experts express different viewpoints. For some, risks are mainly a matter of urban security, so a stronger role for the Ministry of Interior and ONEMI is proposed. For others, risks should be managed from an urban regulation perspective, and hence MINVU should play a more important role. Two interviewees instead propose DRR as a transversal criterion or value influencing every sector's policy, from public investment to the way of conceiving the city. Regardless of the emphasis, there is agreement amongst the interviewees on the need for a multisectoral system able to centrally provide criteria to guide local implementation of DRR policy for the city. This idea is supported by local governments' authorities despite this likely imposing an even greater top-down approach to regulation.

The third topic is the insufficient incorporation of natural hazard risks into regulation. Interviewees agree that the main hurdles in this regard is that there is no formal indication on how to do it. Thus, for example, although natural hazards information is required in the process of developing a new communal regulatory plan, it is not mandatory to do something with it, such as incorporate hazardrelated zoning in the plan. This way, risk information constitutes an input for the process of developing a new plan, but not necessarily an input for the plan itself (i.e., for the outcome). Thus, risks become one amongst several subjective considerations in the plan, such as defining the maximum height of buildings in the comuna, and therefore is subject to political will and intention to be included in a plan. The cause of this is perhaps rooted in the philosophy behind regulation:

First of all, [DRR] has never been an important variable in the regional, intercommunal, or communal planning. Although it appears [in the regulation], only by looking at the normative

\footnotetext{
${ }^{5}$ Law 21,074: Strengthening of the regionalization of the country was published in February 2018 and essentially changes the government's structure at the regional and metropolitan levels. As a result, government at the regional level will have both a presidential delegate designated directly by the President, and a regional governor elected democratically (Ministerio del Interior y Seguridad Publica 2018).
} 
framework you realize it has not been a relevant element. Therefore, neither [it is] the management. [...] The risk component was not an important component in that moment [when regulations were created]. Some elements are, such as flooding, which are recognized, but not addressed enough [2].

Indeed, no interviewee identifies risk as a driver for either urban expansion, development, or regulation update. Instead, changes in urban regulation have been introduced to, e.g., eradicate social dwellings to the periphery of the city (Rugiero 2011), or to change (move, remove) the urban limit to favour liberalization of the real estate market (Petermann 2006). In general, "regulatory plans evolve due to population dynamics, not risks'" [16].

\subsubsection{Tackling seismic risk with safe buildings}

Stemming from the previous discussion, the third theme specifically addresses seismic risk. From an urban planning expert, the answer is direct:

The urban planning of Santiago has not incorporated seismic risk as a critical variable. Seismic risk does not appear [in the planning instruments] with the importance it should. Although there exists zoning according to seismic risk, this is not in the planning instruments [3].

Seismic risk is a "hidden problem" [2] that is not addressed in urban regulation because it is perceived to be solved elsewhere. Earthquakes are seen to be dealt with from a technological perspective, with an adequate design and construction practice that is constantly improving and updating its security standards (Rivera et al. 2019). The main actor in this system is the professional structural engineering community. Organized through renowned individuals and institutions (e.g., professional associations), the community generates and pushes for changes, updates, and enforcement of the seismic design codes. The role of the state is also recognized through two main actors: Instituto Nacional de Normalización (National Institute of Normalization, INN), organism overseeing the discussion for update or creation of new standards and the publication of the codes, and MINVU, which makes building standards legally mandatory.

The engineering community carries the responsibility for proper design and construction of the built environment. Interviewees acknowledge rigorousness, ethics, and pride of the earthquake engineers as the relevant features around Chile's successful seismic culture and history. With a long tradition and overall good results, interviewees agree that earthquakes are somehow a solved issue in the country and that buildings will not collapse in future events. Instead, concerns arise about emergency management and logistics capacities after a future earthquake in Santiago. The earthquake engineering experts agree on this, showing a confidence on the Chilean practice and its constant upgrade and improvement. The concept of a city increasingly better prepared and physically growing into a safer state appears:

There is a somehow automatic protection process: what has not fallen yet, is ok; what has fallen, is not there anymore; what was damaged, is repaired to the current standards [7].

Experts agree that rules are followed in Chile. From a planning perspective, although the weaknesses of the system are acknowledged, regulation-following has contributed to a mostly formal growth of the city, especially in Santiago (Contrucci 2008). This is a distinctive feature of Chile when compared 
to other Latin American countries where illegal settlements constitute a major urban problem [4]. Similarly, in an earthquake engineering context, rule-following has led to a highly effective quality control system for both design and construction of buildings. Structural design projects are subject to an independent review, and then both design compliance and construction quality are verified in the field. Although this cultural formality and compliance is attributed in part to Chilean idiosyncrasy, experts agree that frequent highly destructive urban earthquakes, fear, and "seismic trauma" [8] explain why Chile has been successful in implementing and enforcing earthquake engineering-related regulation.

\section{Discussion}

Overall, results reveal four conditions present in Santiago: (i) rapid and sustained development of the city, (ii) heavy reliance on building codes and construction practice to address earthquake risk, (iii) trusted and well regarded scientific and technical communities, and (iv) a population and institutions that comply with policies and regulation. Combined, these conditions configure a highly enabling environment for increasing the seismic resilience of the city.

Santiago will continue to grow while it remains the economic engine of the country. Sustained growth brings new constructions and the renewal of the building stock which can be interpreted as a step towards seismic safety in a city developing mostly with good-quality, code-compliant RC construction. However, this situation is simultaneously leading to a more fragile condition, wherein an increased responsibility for achieving seismic resilience is imposed almost exclusively on the single thread of engineering and construction practice.

The shift of the construction sector to a more generalized use of RC does not respond to a riskoriented building policy. Instead, it is led by market forces such as costs of land, materials, and labour, changes in speed and efficiency of building technologies, availability of qualified workforce, and smoother post-sales service for real estate companies. If generalized seismic safety is an unintended outcome of market forces, then its sustainability over time is not guaranteed. Moreover, only a very limited number of structural typologies are used for residential structures in Chile, especially for apartment buildings 6 storeys high or taller (Santa María et al. 2017), leading to a more homogeneous built environment (Vergara 2017). An unintended consequence of high code compliance and homogeneous building stock is a high fragility to earthquakes that exceed design levels, and widespread susceptibility to damage induced by deficiencies in the code. Throughout its history, every large earthquake has tested the Chilean building practice and evidenced some shortcomings. Noticing and improving these deficiencies mostly relies on observing the damage patterns after infrequent and damaging earthquakes. The code deficiencies are thus likely to accumulate for long time (e.g., decades) in the built environment before any adjustment is introduced in the code, accumulating these fragilities over time.

Take the unexpected brittle structural damage observed in RC buildings after the 2010 earthquake as an example. The damage was partly attributed to small wall thickness and the lack of mandatory confinement in shear walls boundaries and web (Jünemann et al. 2016). The great performance of shear wall RC buildings in the 1985 Chilean earthquake allowed a progressive decrease of average wall thickness due to architectural reasons and parking needs. Similarly, the update of the building code published after this earthquake - in 1996-removed the mentioned requirement of confinement (Guendelman et al. 2012). Thus, thousands of structures built between the two earthquakes accumulated these features. After the 2010 disaster, the main seismic design codes were modified twice in less than two years, and the requirement of confinement, amongst other shortcomings, was corrected. Buildings repaired or built after the new codes were published are thus expected to be seismically safer. However, if the 2010 earthquake had been different (e.g., larger or with the epicentre located closer to Santiago), patterns of damage and loss could have been much more severe and widespread. Moreover, no retrofit campaign has been launched to improve the 
structural safety of the buildings constructed before 2011, which will contain the design deficiencies highlighted by the 2010 earthquake and hence are still vulnerable to such earthquake effects.

A further, non-technical consideration, is that although the replacement of old buildings and seismically vulnerable typologies (e.g., adobe houses) with RC or masonry structures means a move toward seismic resilience, the loss of vernacular construction practices also carries cultural issues, such as the loss of heritage and cultural identity, especially in peri-urban and rural areas around cities (Micheletti and Letelier Troncoso 2016). Similar to the widespread use of RC, this subject is not considered in any development policy in a country where real estate development is driven solely by free market. Whilst this is not addressed in this research, is an example of socio-cultural issues not accounted for in urban (re)development policy and requires further consideration.

Moving beyond buildings, the results of this research show how natural hazard risks are not a driver or even a consideration for urban development in Santiago, especially in the case of earthquakes. The current institutional and legal framework for urban development, planning, and DRR is weak and outdated and has failed to address natural hazard risks in a comprehensive way. Historically, the Chilean approach for seismic resilience has been purely rational, relying almost blindly in safe buildings and therefore in the local earthquake academic and professional communities to constantly improve the way they are produced. This approach has proven to be successful after decades of experience and sustained attention stemming from the devastating impacts of frequent large subduction earthquakes. However, the sole reliance on individual buildings to account for seismic safety has also hindered the development of a comprehensive DRR approach for the case of earthquakes, such as preparedness at the individual and household levels, and an adequate governance of natural hazards risk at the city level.

The advancement of knowledge regarding Santiago's seismicity and the evidence of activity in the SRF are challenging this historical approach. In the case of building codes, the fact that they are developed and constantly improved for subduction earthquakes raises a warning about what the actual

performance of these safe buildings would be in the event of a crustal earthquake (Estay et al. 2016). In terms of urban planning, the current lack of tools and mechanisms to prevent further urbanization and occupation of risk-prone areas, such as the trace of the SRF, also entails an immediate challenge for implementing changes in the corresponding risk governance, institutions, and planning tools (Vargas Easton et al. 2018). Furthermore, the impacts of an earthquake in the SRF would be mostly local (i.e., at city level) unlike what happens with large subduction earthquakes which often reach a national scale, further stressing the urban risk governance capacities and institutions.

All the above shows a need for diversifying the way seismic risk is handled in Chile, especially at the urban level. The lead of this process could be taken by the scientific community, one of the most trusted DRR stakeholders in the country (Bronfman et al. 2016). It is important, though, that this discussion does not consolidate the current exclusively technocratic approach to earthquake DRR, and instead provides space for the co-creation of plans and tools at the community and urban levels to tackle the portion of risk that is not taken by the safe buildings already in place. Rule-following society and institutions can be led to a more resilient state if proper leadership is put in place. Failing to do so implies that the city will not evolve together with its risks, leading to decay and overall reduced seismic resilience. Hopefully, the imminent passing of the law replacing ONEMI and creating a new DRR institution in the state-which sits in Congress since the 2010 disaster-will provide the political, administrative, legal, and financial means and long-term vision to do so.

\section{Conclusions}

The development of the city of Santiago in the last 25 years is challenging present and future Chilean earthquake engineering. Its pace of urban (re)development and the spatiotemporal dynamics of its seismic exposure require that construction practice and planning evolve constantly and in synchrony 
with risk, which dynamics are not only associated to that of its components' but also to how the notion of risk changes with the evolution of knowledge. Recent findings about the city's seismicity can change the understanding of the seismic risk and the way the city itself relates and interacts with its territory in the future.

The main contribution of this article is addressing seismic exposure from an interdisciplinary perspective, considering its spatiotemporal dynamics, and using mixed methods as a comprehensive research approach. A new method to develop exposure models for Chile is proposed based on the census and public databases. The exposure models developed for Santiago can be used as inputs for SRA and thus study the relative evolution of seismic risk in time due to dynamic exposure. The exposure modelling method can be applied elsewhere in Chile and can be used with the same periodicity of the census to assess a new epoch. Qualitative data obtained with the interviews prove valuable to explain the physical phenomena of Santiago's growth beyond the numbers, acknowledging that physical urban phenomena are mainly a consequence of socio-political conditions and decisions. This research represents an effort to bridge seismic engineering with urban planning and policymaking.

Historical seismic performance underpins the way that Chile has managed its earthquakes to date. However, perceiving earthquake risk as a non-issue based on experience and high local compliance with seismic codes can lead to overconfidence that could become harmful. If engineering fails to incorporate new hazard and risk knowledge fast into codes, practice, and retrofitting efforts, or if planning does not evolve and fails to incorporate a DRR perspective to build the city of the future, it is unlikely that Santiago will develop into a safer condition.

The findings of this research support one main recommendation: the diversification of the mechanisms providing seismic resilience for Santiago. Structural resistance of individual buildings cannot be the single point of failure of such complex urban system and other forms of preparation should be put in place as back up and complement. Thus, a concerted effort to include evolving risks in planning, earthquake engineering, and DRR actions is imperative to increase preparedness and therefore resilience before the next large earthquake strikes. This can be exemplified with the case of the SRF, which now calls for its incorporation into the seismic hazard assessment feeding structural design and in urban planning instruments, together with the development of a preparedness programme for the communities closer to the trace of the fault. This aims to acknowledge and "formalize" the relationship between the planning instruments and the city's surrounding geography, to encounter the citizens much closer with the natural hazards they coexist with daily, and to introduce redundancy into the system through a preparedness "social safety net". These actions would kickstart a shift away from the almost blind reliance on buildings to a more comprehensive approach to increase seismic resilience.

\section{Acknowledgements}

The authors thank the experts who generously participated in the interviews. Funding was provided by the National Commission for Scientific and Technological Research of Chile (CONICYT) through Becas Chile programme, Masters scholarship \#73181077 and PhD scholarship \#72190127. Also, the support and funding of UCL's EPICentre and Centre for Urban Sustainability and Resilience (USAR) is recognised.

\section{References}

Aguirre, Paula, Jorge Vásquez, Juan Carlos de la Llera, Juan González, and Gabriel González. 2018. “Earthquake Damage Assessment for Deterministic Scenarios in Iquique, Chile." Natural Hazards 92 (3): 1433-61. https://doi.org/10.1007/s11069-018-3258-3. 
Aliste, Enrique, and Caroline Stamm. 2017. "Hacia una geografía de los conflictos socioambientales en Santiago de Chile: lecturas para una ecología política del territorio." Revista de Estudios Sociales, no. 55 (June): 45-62. http://dx.doi.org/10.7440/res55.2016.03.

Banzhaf, Ellen, Sonia Reyes-Paecke, Annemarie Müller, and Annegret Kindler. 2013. "Do Demographic and LandUse Changes Contrast Urban and Suburban Dynamics? A Sophisticated Reflection on Santiago de Chile." Habitat International 39 (Supplement C): 179-91. https://doi.org/10.1016/j.habitatint.2012.11.005.

Boano, Camillo, and Francisco Vergara-Perucich, eds. 2017. Neoliberalism and Urban Development in Latin America. The Case of Santiago. London: Routledge.

Bravo, David, Osvaldo Larrañaga, Isabel Millán, Magda Ruiz, and Felipe Zamorano. 2013. "Informe final comisión externa revisora del Censo 2012." Santiago: Instituto Nacional de Estadísticas.

Bronfman, Nicolás C., Pamela C. Cisternas, Esperanza López-Vázquez, and Luis A. Cifuentes. 2016. "Trust and Risk Perception of Natural Hazards: Implications for Risk Preparedness in Chile." Natural Hazards 81 (1): 307-27. http://dx.doi.org/10.1007/s11069-015-2080-4.

Cabrera, Tamara, Gael Boulicault, Matías A. Hube, and Hernán Santa María. 2018. "Empirical Fragility Curves for Masonry Houses Using Data from Two Earthquakes in Chile." In Proceedings of the 16th European Conference on Earthquake Engineering 16ECEE. Thessaloniki, 18-21 June 2018.

Cardona, Omar-Darío, Gabriel A. Bernal, Daniela Zuloaga, Mario A. Salgado-Gálvez, and Diana González. 2017. "Amenaza y riesgo sísmico del Cono Sur." REDER 1 (1): 43-69.

Contrucci, Pablo. 2008. "El Crecimiento de Santiago: Tendencias y Escenarios Futuros." In Mercado y Ciudad: Desafíos de Un País Urbano, Pablo Allard, ed., 9-24. Santiago: Banco BBVA y Observatorio de Ciudades UC, Facultad de Arquitectura, Diseño y Estudios Urbanos, Pontificia Universidad Católica de Chile.

CSN. 2020. "Grandes terremotos en Chile." Centro Sismológico Nacional. http://www.csn.uchile.cl/sismologia/grandes-terremotos-en-chile/ (last accessed 5 February 2020).

de la Llera, Juan Carlos, Felipe Rivera, Magdalena Gil, and Ursula Schwarzhaupt. 2018. "Mitigating Risk through R\&D+Innovation: Chile's National Strategy for Natural Disaster Resilience." In Proceedings of the 16th European Conference on Earthquake Engineering 16ECEE. Thessaloniki, 18-21 June 2018.

de Mattos, Carlos, Luis Fuentes, and Felipe Link. 2014. "Tendencias recientes del crecimiento metropolitano en Santiago de Chile. ¿Hacia una nueva geografía urbana?" Revista INVI 29 (81): 193-219.

Estay, N. P., G. Yáñez, S. Carretier, E. Lira, and J. Maringue. 2016. "Seismic Hazard in Low Slip Rate Crustal Faults, Estimating the Characteristic Event and the Most Hazardous Zone: Study Case San Ramón Fault, in Southern Andes." Nat. Hazards Earth Syst. Sci. 16 (12): 2511-28. https://doi.org/10.5194/nhess-162511-2016.

Galetovic, Alexander, ed. 2006. Santiago. Dónde estamos y hacia dónde vamos. First. Santiago: Centro de Estudios Publicos CEP.

Geiß, Christian, Anne Schauß, Torsten Riedlinger, Stefan Dech, Cecilia Zelaya, Nicolás Guzmán, Mathías A. Hube, Jamal Jokar Arsanjani, and Hannes Taubenböck. 2017. "Joint Use of Remote Sensing Data and Volunteered Geographic Information for Exposure Estimation: Evidence from Valparaíso, Chile." Natural Hazards 86 (1): 81-105. https://doi.org/10.1007/s11069-016-2663-8.

Guendelman, T., Saragoni, G., Verdugo, R., 2012. Chilean emergency seismic design code for building after EI Maule 2010 earthquake. In Proceedings of the $15^{\text {th }}$ World Conference on Earthquake Engineering 15WCEE. Lisbon, 24-28 September 2012.

Gil, Magdalena. 2016. "Catastrophe and State Building: Lessons from Chile's Seismic History." PhD Thesis, New York: Columbia University.

INE. 2018. "XIX censo nacional de población y vivienda [19th national census of population and housing]." Santiago: Instituto Nacional de Estadísticas. 
Joffe, Helene. 2012. "Thematic Analysis." In Qualitative Research Methods in Mental Health and Psychotherapy: An Introduction for Students and Practitioners, David Harper and Andrew R. Thompson (eds.), 209-23. Chichester: Wiley-Blackwell.

Jünemann, Rosita, Juan C. de la Llera, Matías A. Hube, Jorge A. Vásquez, and Matías F. Chacón. 2016. "Study of the Damage of Reinforced Concrete Shear Walls during the 2010 Chile Earthquake." Earthquake Engineering \& Structural Dynamics 45 (10): 1621-41. https://doi.org/10.1002/eqe.2750.

Lee, Ji Yun, Henry V. Burton, and David Lallemant. 2018. "Adaptive Decision-Making for Civil Infrastructure Systems and Communities Exposed to Evolving Risks." Structural Safety 75 (November): 1-12. https://doi.org/10.1016/j.strusafe.2018.05.001.

López-Morales, Ernesto. 2016. “Gentrification in Santiago, Chile: A Property-Led Process of Dispossession and Exclusion." Urban Geography 37 (8): 1109-31. https://doi.org/10.1080/02723638.2016.1149311.

McCracken, Grant. 1988. The Long Interview. Qualitative Research Methods Series, Volume 13. California: SAGE Publications, Inc.

Micheletti, Stefano, and Francisco Letelier Troncoso. 2016. "Damnificados de La Reconstrucción PostTerremoto: Efectos Del Modelo En El Hábitat Rural Del Maule." Revista INVI 31 (86): 17-58. https://doi.org/10.4067/S0718-83582016000100002.

Ministerio del Interior y Seguridad Publica. 2018. Ley 21074: Fortalecimiento de la regionalización del país. https://www.leychile.cl/Navegar?idNorma=1115064\&buscar=21.074 (last accessed 16 September 2019)

MINVU and INE. 2018. "Metodología para medir el crecimiento urbano de las ciudades de Chile." 360. Monografías y Ensayos. IX Ciudad y territorio. Santiago: Ministerio de Vivienda y Urbanismo. https://catalogo.minvu.cl/cgi-bin/koha/opacdetail.pl?biblionumber=24598\&shelfbrowse_itemnumber=8033 (last accessed 5 February 2020)

OECD. 2012. "Redefining 'Urban': A New Way to Measure Metropolitan Areas." OECD Publishing. https://www.oecd-ilibrary.org/urban-rural-and-regional-development/redefiningurban_9789264174108-en (last accessed 5 February 2020)

Petermann, Alexandra. 2006. “¿Quién extendió a Santiago? Una breve historia del límite urbano, 1953-1994." In Santiago. Dónde estamos y hacia dónde vamos, Alexander Galetovic, ed., 205-30. Santiago: Centro de Estudios Publicos CEP.

Pina, F. E., and P. González. 2014. "Estimating Risk for Santiago, Chile Due to Deep Intraplate and Interface Earthquakes." In Proceedings of the 10th National Conference in Earthquake Engineering 10NCEE. Anchorage, AK, 21-25 July 2014.

Pittore, Massimiliano, Marc Wieland, and Kevin Fleming. 2017. "Perspectives on Global Dynamic Exposure Modelling for Geo-Risk Assessment." Natural Hazards 86 (1): 7-30. https://doi.org/10.1007/s11069016-2437-3.

Plano, Vicki L. 2017. “Mixed Methods Research." The Journal of Positive Psychology 12 (3): 305-6. https://doi.org/10.1080/17439760.2016.1262619.

Rauld, Rodrigo, Francisco Medina, Felipe Leyton, and Sergio Ruiz. 2015. "Mapa de Microzonificación SismoGeológica Para Chile." In XIV Congreso geológico chileno, 106-9. La Serena, 4-8 October 2015.

Rivera, Felipe. 2018. "Understanding the Temporal Dynamics of Seismic Exposure in Santiago, Chile." Master thesis, London: University College London.

Rivera, Felipe, Tiziana Rossetto, and John Twigg. 2019. "Understanding Earthquake Resilience in Chile: The Pros and Cons of Safe Buildings." In 2019 Conference of the Society for Earthquake and Civil Engineering Dynamics SECED. London, 9-10 September 2019.

Romero, Hugo, Alexis Vásquez, Claudio Fuentes, Marcela Salgado, Andreas Schmidt, and Ellen Banzhaf. 2012. "Assessing Urban Environmental Segregation (UES). The Case of Santiago de Chile." Ecological Indicators 23 (December): 76-87. https://doi.org/10.1016/j.ecolind.2012.03.012. 
Rugiero, Ana María. 2011. "Experiencia chilena en vivienda social. 1980-1995." Revista INVI 13 (35). http://www.revistainvi.uchile.cl/index.php/INVI/article/view/567.

Santa María, Hernán, Matías A. Hube, Felipe Rivera, Catalina Yepes-Estrada, and Jairo A. Valcárcel. 2017. "Development of National and Local Exposure Models of Residential Structures in Chile." Natural Hazards 86 (1): 55-79. https://doi.org/10.1007/s11069-016-2518-3.

Scholz, Christopher H. 2002. The Mechanics of Earthquakes and Faulting. Second. Cambridge: Cambridge University Press. https://doi.org/10.1017/CBO9780511818516.

Silva, Vitor, Helen Crowley, Kishor Jaiswal, Ana Beatriz Acevedo, Massimiliano Pittore, and Murray Journey. 2018. "Developing a Global Earthquake Risk Model." In Proceedings of the 16th European Conference on Earthquake Engineering 16ECEE. Thessaloniki, 18-21 June 2018.

Stein, Ross S., and Shinji Toda. 2013. "Megacity Megaquakes-Two Near Misses." Science 341 (6148): 850-52. https://doi.org/10.1126/science.1238944.

UN DESA. 2018. “World Urbanization Prospects." 2018. https://esa.un.org/unpd/wup/ (last accessed 16 September 2019).

Vargas Easton, Gabriel, Jorge Inzulza Contardo, Sonia Pérez Tello, Daniela Ejsmentewicz Cáceres, and Catalina Jiménez Yáñez. 2018. “¿Urbanización fallada? La Falla San Ramón como nuevo escenario de riesgo sísmico y la sostenibilidad de Santiago, Chile." Revista de Urbanismo, no. 38 (June): 1-20. https://doi.org/10.5354/0717-5051.2018.48216.

Vaziri, P, M.L. Zoback, T.H.P Tabucchi, and C.M. Cabrera. 2012. "Comparative Analysis of Economic and Human Casualty Seismic Risk for South American Andean Capital Cities." In Proceedings of the $15^{\text {th }}$ World Conference on Earthquake Engineering 15WCEE. Lisbon, 24-28 September 2012.

Vergara, Jorge. 2017. "Verticalización. La edificación en altura en la Región Metropolitana de Santiago (19902014)." Revista INVI 32 (90): 9-49.

Vicuña Del Río, Magdalena. 2017. "Planificación metropolitana de Santiago: cambios de estilo frente a las recientes transformaciones urbanas." Revista Iberoamericana de Urbanismo, no. 13. https://www.raco.cat/index.php/RIURB/article/view/328648. 